\title{
Bernard Barthet, Science, histoire et thématiques ésotériques chez les Jésuites en France (1680-1764)
}

Bibliographie (sources imprimées et études), index. Préface de JeanPierre Brach

Pessac, Presses universitaires de Bordeaux, coll. « Identités religieuses », 2012, 560 p.

Jean-Pierre Laurant

\section{OpenEdition}

Journals

Édition électronique

URL : http://journals.openedition.org/assr/25164

DOI : $10.4000 /$ assr.25164

ISSN : $1777-5825$

Éditeur

Éditions de l'EHESS

Édition imprimée

Date de publication : 30 décembre 2013

Pagination : 133

ISSN : 0335-5985

\section{Référence électronique}

Jean-Pierre Laurant, «Bernard Barthet, Science, histoire et thématiques ésotériques chez les Jésuites en France (1680-1764) », Archives de sciences sociales des religions [En ligne], 164 | 2013, mis en ligne le 18 février 2014, consulté le 21 septembre 2020. URL : http://journals.openedition.org/assr/25164 DOI : https://doi.org/10.4000/assr.25164

Ce document a été généré automatiquement le 21 septembre 2020

(C) Archives de sciences sociales des religions 


\section{Bernard Barthet, Science, histoire et thématiques ésotériques chez les Jésuites en France (1680-1764)}

Bibliographie (sources imprimées et études), index. Préface de JeanPierre Brach

Pessac, Presses universitaires de Bordeaux, coll. «Identités religieuses », 2012, $560 \mathrm{p}$.

Jean-Pierre Laurant

\section{RÉFÉRENCE}

Bernard Barthet, Science, histoire et thématiques ésotériques chez les Jésuites en France (1680-1764), Bibliographie (sources imprimées et études), index, Préface de Jean-Pierre Brach.

Pessac, Presses universitaires de Bordeaux, coll. « Identités religieuses », 2012, 560 p. 
Ce travail a fait l'objet d'une thèse à l'École pratique des hautes études en 2008; il s'inscrit dans la ligne du renouveau de l'historiographie de la Compagnie de Jésus, comme le rappelle le préfacier, et s'attache à éclairer sa stratégie de reconquête des esprits dans le prolongement des controverses postridentines. Face aux effets des progrès de la science au $\mathrm{XVII}^{\mathrm{e}}$ siècle tels que les a décrits Jean-Robert Armogathe (Histoire des idées scientifiques et religieuses dans l'Europe moderne, Brepols, 2012), les pères jésuites concentrèrent leurs efforts sur la pédagogie servie par des moyens modernes comme le théâtre, les arts et le "journalisme». Le Journal de Trévoux mobilisa les meilleures plumes de la Compagnie au service du combat pour la vraie connaissance. Après avoir décrit le paysage politico-religieux de la fin du XVII ${ }^{\mathrm{e}}$ siècle avec l'opposition entre gallicans et jansénistes et les progrès du cartésianisme, l'auteur analyse les méthodes utilisées (le cadre d'expression de la mission) dans les controverses suscitées par les "grands débats de société " et l'intervention de la thématique ésotérique dans leur panoplie: une présence liée en partie à la forte personnalité de pères de la génération précédente : Athanase Kircher (m.1680) et son projet de science universelle, ainsi que Gaspard Schott (m.1666). Néanmoins, les scriptores de la Compagnie n'ont jamais utilisé les arguments ésotériques comme une fin en soi, mais ponctuellement, au secours de positions de l'Église qu'ils jugeaient menacées; le recours à la méthode expérimentale étant tout aussi fréquent. S'ils s'opposaient aux rêveries de l'alchimie paracelsienne, la kabbale leur servit à l'approche de l'Yi-King, tout comme ils avaient mis la vision métaphysique développée par Leibniz au service de leur lutte contre le « matérialisme » cartésien.

2 En 1729, le père Regnault publia une Physique nouvelle, véritable «encyclopédie philosophique de la nature ", œuvre pédagogique par excellence qui tentait de définir une position scientifique de la compagnie sur des questions aussi importantes que l'existence de la "matière subtile » ou la nature du vide après les travaux de Newton sur la gravitation. L'histoire fut également au premier rang de leurs préoccupations avec la construction d'un discours sur la mythologie antique compatible avec la morale chrétienne et la chronologie biblique, L'Origine des fables (1724) de Fontenelle leur servant de guide. Comment constituer une chronologie universelle susceptible d'intégrer l'Antiquité classique et les connaissances ramenées de Chine par les pères? C'est en réponse à l'ensemble de ces questions qu'intervient la thématique ésotérique. l'adjectif seul dont il attribue la première mention au Journal de Trévoux, 1752 (à la suite du Trésor de la langue française), alors qu'il est présent dix ans plus tôt dans un texte maçonnique de La Tierce, Nouvelles Obligations... Les thématiques choisies seront 
effectivement reconnues comme telles (id est ésotériques) par le XIx ${ }^{e}$ siècle, à savoir, l'alchimie, le rôle des mystères antiques transmis par initiation, la kabbale chrétienne et la magie naturelle en héritage de la Renaissance enfin, la question qui deviendra centrale du magnétisme ; en revanche, celle de l'annonce par les oracles sibyllins de la venue du Sauveur perdit de son acuité.

Les Trévousiens les ont utilisées "à la carte " passant de l'hostilité envers l'alchimie (héritée de Kircher), à l'occasion des publications de Van Helmont, à la récupération de l'hermétisme par le biais du pythagorisme (Michel Mourgues, Plan théologique du pythagorisme..., 1712). Le chevalier Ramsay, ancien secrétaire de Fénelon, obtenait aussi leurs suffrages pour avoir montré comment Hermès et Pythagore conduisaient en fait à la révélation. Dans le même esprit, ils ont redécouvert la kabbale chrétienne (la bonne kabbale) : une piste pour expliquer les 64 hexagrammes de l'Yi-King de Fo Hi et le mode de pensée binaire qui permettait des spéculations sur le zéro et le chaos primordial (le calcul intégral de Leibniz était alors appelé en secours). En matière de magie, leur position restait nuancée, fondée sur la distinction classique entre magie naturelle et goétie, ils s'abritaient derrière les progrès de la "physique", appuyés sur les dictionnaires de Bayle ou de Furetière, cherchant à intégrer la nouvelle approche de la nature dans une contemplation de la sagesse divine. Il en allait de même pour la question du magnétisme, les pères hésitant entre l'action du malin et l'explication de la cure par la "sympathie" observable dans la nature; ils accueillirent ainsi favorablement le travail annonciateur de la révélation de Digby sur La poudre de sympathie. Les chapitres suivants portent sur la défense des oracles et des prophéties comme préfiguration de la révélation et que les exégèses critiques attaquaient; les Trévousiens s'en remettaient à la tradition patristique, elle aussi victime d'un antiplatonisme, selon eux, un peu court.

5 Si les thématiques ésotériques étaient moins visibles dans ces controverses, elles réapparaissent à propos de "l'énigme des emblèmes et des médailles", support important de la rhétorique des jésuites où l'on voit s'inviter le débat sur les hiéroglyphes, porté par la vogue " égyptianisante » (le Séthos de l'abbé Terrasson, 1731), en écho à l'Oedipus Egyptiacus (1652-1654), œuvre maîtresse du père Kircher.

6 À la fois savants et engagés, les scriptores ont donc intégré à leur pédagogie bon nombre de thèmes ésotériques, soucieux de ne pas abandonner ce terrain fertile à la théosophie protestante, par exemple, et dans l'intention de contrôler les excès de l'imagination, fertile en ces domaines, par une solidité doctrinale jointe à la pratique des exercices de saint Ignace. Ce travail éclaire de façon remarquable la mise en place des grands débats du XIXe siècle sur les rapports entre science et foi dans lesquels l'ésotérisme s'est voulu créateur de pont. 